\title{
Educação complexa para uma nova política de civilização
}

\section{Complex education for a new policy of civilization}

\author{
Izabel Petraglia*
}

\begin{abstract}
RESUMO
Este artigo apresenta reflexões a partir de três eixos interdependentes e complementares, que têm norteado nossas ações educacionais. Inicialmente, procuramos conhecer o sujeito do processo educacional, considerando as influências recebidas da Modernidade e seus reflexos no presente. Para esse sujeito, que é antes de tudo um ser complexo, imerso no caldo cultural de seu tempo e lugar, apostamos numa educação complexa, capaz de promover questionamentos ético-políticos que possam influenciar o seu processo auto-organizador. Uma educação complexa também pode fazer emergir a tomada de consciência de nossa cidadania planetária e influir positivamente no devir do Planeta. Para isso é fundamental que se estabeleça uma nova política de civilização, que valorize a convivência saudável e amorosa do sujeito consigo mesmo, com o outro, com as diversidades, enfim com o meio ambiente.
\end{abstract}

Palavras-chave: sujeito; educação complexa; ecosofia; política de civilização.

\footnotetext{
ABSTRACT

This article presents reflections based upon three interdependent and complementary axes which have directed our educational actions. At first we try to get to know the subject of the educational process, taking

* Doutora em Educação pela USP e Pós-Doutora pela EHESS, Paris. Professora do Programa de Pós-Graduação em Educação da Universidade Nove de Julho e Coordenadora do NIIC - Núcleo Interinstitucional de Investigação da Complexidade, em São Paulo. Correio eletrônico: izabelpetraglia@terra.com.br
} 
into account the influences he received from modernity and its effects in the present time. With regard to this subject, who is first of all a complex being, immersed in the cultural hotbed of its time and space, we bet on a complex education, able to promote ethico-political questioning that can influence its self-organizing process. A complex education can also foster the emergence of the awareness of our planetary citizenship and it can have a positive impact upon the transformation of the planet. In order to achieve this, it is fundamental to establish a new civilization policy which values the subject's healthy and loving conviviality with himself, with the others, with the diversities and at last with the environment.

Keywords: subject; complex education; ecosophy; civilization policy.

\begin{abstract}
"A natureza da prática educativa, a sua necessária diretividade, os objetivos, os sonhos que se perseguem na prática não permitem que ela seja neutra, mas política sempre. É a isto que eu chamo de politicidade da educação, isto é, a qualidade que tem a educação de ser política. A questão que se coloca é saber que política é essa, a favor de quê e de quem, contra o quê e contra quem se realiza".
\end{abstract}

Paulo Freire

Para se pensar a complexidade no processo educacional, vale refletir sobre o caráter político da educação, de que nos lembra Paulo Freire, quando questiona "a favor de quê e de quem, contra o quê e contra quem a educação?" Quem é o autor desse processo? Se não há educação neutra, se toda educação é, antes de tudo, política, temos que verificar o que entendemos pelo termo, tão desgastado em nossos dias. Que política é essa que satisfaria os educadores? Que sujeito e que sociedade desejamos formar? Que identidade podemos construir e que mundo habitar?

O termo política, do grego, indica os procedimentos relativos à pólis, cidade, Estado. Associa-se também a outras noções, tais como convivência, pluralidade, exercício de interesses, poder, conquista, conflito, igualdade. Desde Aristóteles, a política era entendida como o que se relaciona à busca de ações para o bem-estar individual e dos grupos. Esse bem- estar, para ser coletivo, não pode ser opressivo, tampouco egocêntrico ou compartimentado.

O pensamento político não pode reduzir-se ao econômico, mas tem que englobar e transcender os povos e as culturas. Há de se manter as aspirações fraternais e libertárias. Trata-se de uma política de civilização, que busque a 
realização humana e sociedades mais justas. Precisamos, urgentemente, de uma política planetária, que contemple uma educação a favor dos seres humanos, porque somos e compartilhamos de uma cidadania terrestre.

\section{O sujeito e a modernidade: reflexos no presente}

Se pensarmos no movimento da história das sociedades e da humanidade, desde o Renascimento até a Modernidade, constatamos a evolução do conhecimento, que impulsionou possibilidades, insuficiências e contradições que hoje tentamos assimilar ou superar. Se foi na Modernidade que surgiram as utopias emancipatórias, foi lá também que se formaram as sociedades capitalistas, o recrudescimento da barbárie, a ascensão da burguesia e a crueldade da escravidão.

Surgiram importantes exercícios de democracia, possibilidades de libertação religiosa do sujeito em relação à Igreja, dos povos oprimidos em relação aos seus colonizadores ou opressores. Mas também foram inaugurados diversos modelos de dominação e consagraram-se novos instrumentos de poder normatizadores e fiscalizadores das sociedades e instituições disciplinares - com organização dos espaços, controle e vigilância - como tão bem já nos apontou Foucault (2005).

$\mathrm{O}$ autor entende que o poder em si mesmo não existe, mas que se faz presente nas práticas e nas relações. Reconhece que os interesses hegemônicos de diferentes grupos sociais determinam situações de poder, mas que essa não é sua única manifestação, pois ele está presente nos diversos cenários da vida humana.

Foucault aponta também duas esferas de poder, que são a ciência e a cultura, cujas manifestações emergem de segmentos diferentes, mas não contraditórios - complementares: das instituições e das relações interpessoais. Apesar de se utilizarem de dinâmicas próprias, os dois contingentes são responsáveis pela perpetuação da legitimidade das ações e dos discursos de poder que surgiram para escamoteá-lo nas sociedades modernas.

No Humanismo, mais intensamente nos séculos XV e XVI, o ser humano se revê como referência, o centro de si mesmo e isso o permitia ser o senhor da natureza. Depois aprendemos, com os estudos da psicanálise, a partir do final do século XIX, que temos um corpo além da alma e que a sexualidade é o berço do prazer, do amor e da vida. Aprendemos ainda sobre a existência de uma realidade psíquica, em que o sujeito é regido, igualmente pelo inconsciente, 
que o ultrapassa.

A ética também é afetada na Modernidade, não só com os inúmeros atentados contra a vida, das guerras e genocídios, mas, ainda, com a incapacidade de enfrentamento de novas contradições. Estabelece-se a dualidade e o relativismo em torno do bem e do mal. Quando algumas pessoas ou grupos se crêem do bem, elas se autorizam a cometer o mal, em nome do bem. E a história da humanidade nos mostra isso, com inúmeros exemplos, recorrentes também na Modernidade.

Essa multiplicidade de acontecimentos e mudanças, de um lado nos acenou com promessas de autonomia, de outro nos fez descobrir dependentes, a partir de nossos próprios limites.

A crença no progresso levou-nos à esperança que os desenvolvimentos da ciência, da indústria, da economia mundial e da técnica acabariam com os infortúnios da humanidade. Só mais tarde perceberíamos tais desenvolvimentos como ambivalentes: incapazes de responder aos desejados desígnios de salvação geral e, ao contrário, ainda capazes de criar uma cisão entre tempo e história, entre ciência e ser humano. Além de não justificar ou minimizar a barbárie, ao longo do processo, foi acirrado o individualismo e, com ele, o isolamento do sujeito.

Mas quem é esse que aparece enredado nas teias do tempo e se espelha na história, nas possibilidades e incoerências do passado? De um passado remoto, como também do não distante. Quem é esse que aprendeu a reproduzir, como diz na música, Elis Regina: "Como os nossos pais" ? Cada geração rompe com algumas tradições e costumes, tendendo a modificar sua história e seu habitat. Ainda que salutar e necessário, podendo provocar instabilidade com as imprevisibilidades, já que se perdem referenciais de certeza, mudar um paradigma, além de ser demorado, impõe novas escolhas e, portanto, perdas.

Quem é o sujeito, hoje, que foi gradativamente perdendo a si próprio e se desgarrando de seu tempo, dilacerado por expectativas que não eram, mas ao mesmo tempo eram também as suas, e cuja desconstrução foi se tornando cada vez mais intensa até chegar ao momento presente? Quem é esse ser que não se pensa e tampouco se vê, como declama Pessoa (1980, p. 152-153) em $O$ Guardador de Rebanhos e, ao trazer a alma coberta, se esconde para si e para o outro?

O essencial é saber ver,

Saber ver sem estar a pensar, 
Saber ver quando se vê,

E nem pensar quando se vê

Nem ver quando se pensa.

Mas isso (tristes de nós que trazemos a alma vestida!),

Isso exige um estudo profundo,

Uma aprendizagem de desaprender $[\ldots]$

Nossas reflexões apontam para as vicissitudes do sujeito que, ora acredita, ora não, no que é visível e no que é invisível. Ser complexo é poder oscilar entre tudo e nada; entre o todo e o fragmento; entre ordem e desordem; entre o pulsar da vida e a paradoxal estranheza diante da morte.

Vale lembrar aqui uma comédia da Pandora Filmes, de Hal Salwen, produzida em 1995, intitulada Denise está chamando ("Denise calls up"), que relata os desencontros de um grupo de amigos que nunca se vêem e só se comunicam por meio da técnica, por telefone ou por computador. Estão em busca de emoções, mas não encontram sentido na vida e suas ações, da mesma forma, não produzem qualquer ressonância no outro, tampouco agregam algum valor à própria existência. Trata-se de uma comédia, que também é capaz de apontar para o lado trágico da vida, quando o ser humano, diante do imponderável, não sabe para onde e nem como ou para quê ir a algum lugar.

Camargo (2007) aponta para as convergências dos pensamentos de Carl Gustav Jung e Edgar Morin, cada qual em seu tempo e à sua maneira, na crítica do sujeito moderno. Os dois pensadores consideraram a idéia de re-ligação, tanto na psique como na cultura, como chave para a transformação, em oposição à ênfase no esfacelamento do conhecimento na Modernidade. Compreendem homem e mundo com características que são, ao mesmo tempo, opostas e complementares, como razão e emoção; autonomia e dependência; amor e ódio; altruísmo e egoísmo, numa perspectiva não dual, mas que associa unidade e diversidade.

Jung e Morin apresentam uma concepção trinitária do ser humano, que inclui espécie - homo sapiens; sociedade - ser social; e indivíduo - sujeito complexo; e sugerem reflexão, problematização e contextualização como facilitadoras para a busca de sentido através de um processo educativo ao mesmo tempo pessoal e em comunhão com os outros seres. Ambos os pensadores têm esperança no futuro e entendem que o cidadão planetário é capaz de conviver com as incertezas e respeitar as diferenças nas sociedades multiculturais. Propõem relações de alteridade e solidariedade para o enfrentamento da crise e da barbárie.

As convergências entre Jung e Morin são destacadas também por Camargo (2007), nos âmbitos da ontologia, da epistemologia, das relações humanas, e das 
relações entre os pensamentos mítico-simbólico e lógico-racional.

Bauman, ao refletir sobre o mal-estar da pós-modernidade retoma o livro de Freud, O mal-estar na civilização, publicado em 1930, em que constata que a civilização de outrora já era a modernidade, como a deciframos hoje. Valendo-se de Freud, afirma (1998, p. 8-10):

O princípio de prazer está aí reduzido à medida do princípio de realidade e as normas compreendem essa realidade que é a medida do realista. "O homem civilizado trocou um quinhão das suas possibilidades de felicidade por um quinhão de segurança".

Se lá a segurança ilusória colocava em risco e até rompia com o sonho de liberdade, prazer e felicidade, hoje os reflexos são percebidos na inversão de uns e no abandono de outros valores. Quando se ganha também se perde e isso foi potencializado na contemporaneidade:

Os homens e as mulheres pós-modernos trocaram um quinhão de suas possibilidades de segurança por um quinhão de felicidade. [...] Os malestares da pós-modernidade provêm de uma espécie de liberdade de procura do prazer que tolera uma segurança individual pequena demais (BAUMAN, 1998)

E quem é, hoje, esse sujeito de quem se fala? Atribui-se a ele a função de construir seu conhecimento, de ser o autor de sua própria história e de conquistar sua cidadania. Será ele capaz de enfrentar tais desafios? Estará preparado para essa tarefa formativa? Poderá ser livre e feliz com a passagem do tempo e na convivência com as incertezas?

\section{Uma educação complexa?}

Tantas indagações nos remetem às reflexões de nosso lugar no mundo, das possibilidades reais ou imaginárias e de nossa participação no universo cultural de nosso tempo. A esperança nos faz crer que ainda resta "um sopro 
de vida", título da obra de Clarice Lispector (1999), em que expõe sua busca e suas questões diante da contradição entre vida e morte:

Tenho que ter paciência para não me perder dentro de mim: vivo me perdendo de vista. Preciso ter paciência porque sou vários caminhos, inclusive o fatal beco-sem-saída [...]

Eu queria escrever um livro. Mas onde estão as palavras? Esgotaram-se os significados.

Só na desordem de meus sentidos é que compreendo para mim mesma e é tão incompreensível o que eu sinto que me calo e medito sobre o nada [...]

Eu me tornei intolerável para mim mesma. Vivo numa dualidade dilacerante. Eu tenho uma aparente liberdade, mas estou presa dentro de $\operatorname{mim}[\ldots]$

Eu busco a desordem, eu busco o primitivo estado de caos. É nele que me sinto viver $[\ldots]$.

Acreditamos no processo educativo como um sopro de vida para a humanidade. É preciso esperança para não nos entregarmos ao definitivo caos, para não desistirmos de procurar o sentido da existência, mesmo com a conviç̧ão da transitoriedade e da finitude da condição humana, da interveniência do aleatório.

Uma educação complexa tem o papel de propiciar a reflexão e a ação de resgatar a nossa essência e a nossa humanidade, acenando com novas perspectivas de resistência, emancipação e felicidade. Foucault (2005) nos ensina que para toda manifestação de poder se impõe uma forma de resistência. Morin (2005) reforça a esperança numa ética de resistência. E Guattari (1990, p. 56) também aposta no salto transformador, a partir dos pequenos movimentos, que resistem por expulsarem o pessimismo e a passividade: "Assim, toda uma catálise da retomada de confiança da humanidade em si mesma está para ser forjada passo a passo e, às vezes, a partir dos meios os mais minúsculos".

Essas proposições ético-políticas não se ocupam em decifrar os desafios de nosso devir, mas em resignificar a vida presente e transitória, a partir da transformação do olhar de novas formas de pensar e de agir, que partam da linearidade em direção à complexidade, por meio de um olhar multidirecional.

Para isso, é preciso conviver com a transitoriedade e com a incerteza, aceitando a imprevisibilidade como possibilidade real. Isso não é fácil. É um desafio constante e uma sofrida e necessária aprendizagem que podemos enfrentar com coragem, perseverança e ousadia. $\mathrm{O}$ enfrentamento já é a própria 
ousadia que pressupõe reflexão e auto-crítica perenes na busca de sentido. A crise é válida porque renova a esperança da possibilidade criadora e criativa dos seres humanos.

A problematização que nos estimula a agir e a produzir conhecimentos surge da indignação, do espanto e do encantamento diante dos conflitos da existência que, desde que contextualizados, podem ser compreendidos de maneira saudável em suas multiplicidades complexas.

Trata-se de aprender a condição humana por meio das articulações entre unidade e diversidade intrínsecas aos seres, considerando as inter-relações dos conhecimentos dispersos em disciplinas ou áreas estanques como ciências naturais, humanas, filosofia, arte, religião. Tais conhecimentos serão pertinentes se puderem constituir-se a partir de relações mútuas e influências recíprocas e complementares entre as partes e o todo complexo. O pensamento complexo nos possibilita questionar e conhecer os próprios modos de conhecer, como também nos permite melhor situá-los nas instituições educacionais.

Um tipo de pensamento, oriundo de uma epistemologia complexa, que se propõe a unir e não separar os diferentes aspectos do conhecimento questiona a fragmentação e as insuficiências das especializações como soluções unívocas. Propõe religações e solidariedade na conjugação da ciência com as culturas, das artes e a filosofia, para a construção de uma educação cidadã, comprometida com a formação de sujeitos planetários, éticos e mais felizes.

Da relação educação e complexidade, destacamos algumas idéias que julgamos importantes para que professores e estudantes levem em conta no processo auto-eco-organizador. São elas ${ }^{1}$, as noções de sujeito e homo complexus que habitam os seres humanos; a importância da utilização de diversas linguagens no processo de ensino e aprendizagem; a presença da dialógica na vida até a morte, com suas contradições insuperáveis; a religação dos conhecimentos que culmina com a transdisciplinaridade; a difícil convivência com a incerteza, já apontada anteriormente; a auto-ética que se quer desenvolver e aprender e, para tanto, a proposição de uma reforma do pensamento que associe o linear ao complexo.

Ciampa, em sua obra $A$ estória do Severino e a história da Severina, conta a aventura de uma mulher chamada Severina, que não se conhece e não se percebe sequer como pessoa. Só se enxerga pelo outro, mas aos poucos vai se transformando, à medida que vai se conhecendo. Severina apresenta um pouco de sua história de transformação, na construção de sua identidade (1993,

1 Essas idéias já foram apresentadas em PETRAGLIA, I. Sete idéias norteadoras da relação educação/complexidade. In: ALMEIDA, C.; PETRAGLIA, I. (Org.). Estudos de complexidade. São Paulo: Xamã, 2006, p. 23-36. 
p.110-111):

\begin{abstract}
A gente pode transformar o veneno em remédio [...]. A gente [...] não vai mudando de uma hora pra outra; vai mudando por etapa, devagarzinho; cada dia que a gente vai passando, cada hora, cada minuto, cada segundo da vida da gente, a gente vai sentindo e percebendo as coisas, vendo as coisas de outro ângulo, diferente do que a gente era [...]. Hoje, de jeito nenhum, eu não quero voltar àquela vida que eu tive, àquela vida de miséria, de estado de inferno, porque eu vivia no estado de inferno; hoje eu tenho estados de inferno dentro de mim [...] porque eu sou ser humano [...] Tanto a gente tem dentro de bom, como a gente tem estados de ruins $[\ldots] \mathrm{Eu}$ vou ter muito, muito, muito que mudar [...] a gente ir se transformando permanentemente dentro da gente!.
\end{abstract}

A metamorfose acontece, ou como disse Severina, "vai acontecendo", preservando a identidade. Somos, simultaneamente, a totalidade de nós mesmos e as partes desse todo orgânico, que nos constitui. Somos unidade e multiplicidade de personagens e desempenhamos diferentes papéis ao longo da vida, mesmo quando não o sabemos. A consciência não elimina a incerteza, tampouco minimiza o risco ou a dúvida, mas ao contrário, dá luz ao erro e à ilusão, que são intrínsecos à condição humana, e oportunidade criativa ao exercício de talentos até então não imaginados.

Quando o ser humano adquire consciência de seu processo transformador, pode fazê-lo, a partir de suas crenças e de suas concepções. Torna-se mais autônomo, e toda autonomia pressupõe também dependências de um tempo, uma cultura, uma linguagem, um lugar e de diversas histórias e relações.

$\mathrm{O}$ ambiente altera o meio, que, ao mesmo tempo é alterado por ele. Assim também é o sujeito, que, uno e múltiplo - unitas multiplex em sua compreensão de si, acolhe o auto-exame e a autocrítica para o exercício da auto-eco-organização consciente. O sujeito se percebe na relação de alteridade, quando é capaz de enxergar e reconhecer o outro. $\mathrm{O} \boldsymbol{e} \boldsymbol{u}$ só existe na relação com o $\boldsymbol{t} \boldsymbol{u}$ e é quando surge o nós: dos limites e do respeito, na complementaridade da vida.

Somos novamente cúmplices de Pessoa (1980, p. 242), agora em Passagem das horas, com seu entendimento poético acerca do sujeito que, para saber-se, precisa sentir-se e também ao que o cerca e o constitui, simultaneamente, de maneira recursiva, dialógica e hologramática: 
Para me sentir, precisei sentir tudo,

Transbordei, não fiz senão extravasar-me,

Despi-me, entreguei-me,

E há em cada canto da minha alma um altar a um deus diferente.

Assumir a condição humana é compreender a dialógica: egocentrismoaltruísmo e perceber-se, ao mesmo tempo, homo sapiens-demens, prosaico, poético, desmedido, razoável, sonhador. Assumir a condição humana é também reconhecer, ao mesmo tempo, a diferença e a identidade em si e no outro, como nos aponta Ciampa, mais uma vez (1993, p.112):

Consciência de si e consciência do outro!

Encontra vida: reconhecer o outro como humano e ser reconhecida como tal!

Valoriza a vida: o maior tesouro do mundo.

Sozinha, certamente, não podia ver reconhecida sua humanidade, conseqüentemente não se reconhecia como humana.

Identifica-se como humana.

Identidade humana. Vida!

Uma educação complexa deve ser comprometida com o devir: com o político e o pedagógico, destacando dessa relação o papel dos sujeitos na construção de sua identidade. Há de levar em conta o respeito às diversidades étnicas, religiosas, de gênero, de orientação sexual e as culturas. Há de se valorizar as experiências sensíveis e estéticas; o equilíbrio da afetividade com a sexualidade; da emoção com a razão; da teoria com a prática e estimular a convivência amorosa com o outro, com o meio ambiente.

\section{Ecosofia e política de civilização}

É necessária uma revolução política, social e cultural em escala planetária para o enfrentamento de problemas universais que continuam pendentes. Assim compreende Guattari (1990), quando propõe a ecosofia, que é a articulação ético-política de três ecologias: ecologia mental, que diz respeito às relações do indivíduo consigo mesmo; ecologia social, relativa às relações dos seres humanos e sociedades entre si e ecologia ambiental, que supõe as relações 
dos seres humanos com o ambiente e o planeta. Esse é um novo modo de viver, frente às aceleradas mudanças técnico-científicas e do grande aumento populacional planetário que deve reorientar os objetivos da produção de bens materiais e imateriais.

Morin (2005) compartilha dessa idéia ao propor uma religação ética, que congrega auto-ética - a ética antes de tudo individual e para si, que desemboca ao mesmo tempo numa ética para o outro; sócio-ética - da comunidade que a precede, a engloba e a transcende e; antropoética - a maneira ética da espécie assumir seu destino humano no planeta.

Uma ética complexa pressupõe a compreensão de si e do outro e a consciência planetária e solidária, que propicia o desenvolvimento de um sujeitocidadão democrático, criativo e inserido em seu universo cultural. O sentimento de pertença e de ter uma identidade terrena deve ser equivalente ao de fazer parte da Terra-Pátria, mas também participar de uma sociedade e de uma cultura. Essa perspectiva sugere uma nova política de civilização, a ser introduzida nas ciências humanas, naturais, da saúde, exatas e sociais.

Tal proposição política supõe a regeneração do pensamento político e do conceito chave de cidadania, que associa noções fundamentais de identidade, liberdade e comunidade, mas também leva em conta a democracia cognitiva, que permite o acesso ao conhecimento e não o enclausura em áreas disciplinares. Uma democracia cognitiva não permite encerrar o saber entre os muros de instituições educacionais, mas propõe a transcendência dos limites que o possam reduzir.

Uma nova política de civilização conta com a reforma do pensamento que integra e não isola ou fragmenta e conta com a produção inclusiva de conhecimentos contextualizados, que considera a importância das conexões e inter-relações das partes e do todo.

Morin nos acena, reiteradamente, para a necessidade de se conceber a unidade do múltiplo e a multiplicidade do uno, a partir de um duplo imperativo complexo, como por exemplo, quando afirma que (1997, p. 128-129): “[...] impõe-nos que salvaguardemos a diversidade das culturas e desenvolvamos a unidade cultural da humanidade[...]. A pátria terrestre comporta a salvaguarda das diversas pátrias". Há de se preservar as diferentes culturas e, ao mesmo tempo integrá-las no universo planetário. A consciência de uma comunidade de origem e de uma comunidade de destino nos indica a religação dos seres e dos saberes na teia complexa de uma pátria universal. Logo, não se pode perder de vista a urgência de uma reforma do pensamento que introduz o pensamento complexo norteador das relações antagônicas entre o local e o global, entre as diversas dimensões humanas, de modo a responder positivamente aos desafios da contemporaneidade. 
Precisamos de uma nova aliança entre os seres e destes com a Terra.

Todavia, nosso futuro planetário é incerto e as perspectivas são indeterminadas. A complexidade da ação ou a ecologia da ação, que é relativa ao seu caráter ético e político, nem sempre reflete sua intencionalidade, ou seja, nem sempre os efeitos de nossa ação são aqueles esperados. Temos que contar com o princípio da incerteza, que nos cerca e nos envolve, não nos permitindo controle sobre todas as situações ou perspectivas. O que não significa que devamos ficar estagnados e que não possamos agir, por medo do insucesso, frente ao acaso. Morin nos adverte (MORIN,1997, p. 29):

Não poderemos eliminar a desgraça nem a morte, mas podemos aspirar a um progresso nas relações entre humanos, indivíduos, grupos, etnias, nações [...]. A renúncia ao melhor dos mundos não é, de modo algum, a renúncia a um mundo melhor.

Compreender as transformações da história, do tempo e das culturas e incorporá-las ao contexto educacional, a partir da religação dos saberes, é uma nova visão de mundo. Como também, resistir à barbárie que nos afronta e violenta é participar de uma política de civilização, promovendo solidariedade com esperança numa possível e desejada cidadania planetária.

A cidadania planetária solidária e fraterna supõe o espírito de civismo terreno, o exercício das relações de alteridade, que aponta para o convívio com a diferença e para o diálogo com as contradições. A dialógica não emerge da unidade e do consenso, mas da diversidade e do pluralismo de idéias, que mantém o conflito saudável para a produção do conhecimento. É desse princípio que a complexidade se nutre, associando-lhe o trinômio: ordem, desordem e organização.

Trata-se de uma reforma em profundidade, que integre o futuro incerto do mundo; a aposta nas possibilidades de enfrentamento e intervenção; o estabelecimento de estratégias de ação; o conhecimento pertinente, transdisciplinar e contextualizado com suas religações; a conscientização das urgências e; as responsabilidades humanas.

Concluímos com Morin, na cumplicidade com Heráclito, quando afirma (MORIN, 1997, p. 130): "Escrevemos repetidamente que a única esperança está no improvável. Heráclito, na mesma frase em que reconhecia que o inesperado é 'ilocalizável e inacessível', acrescentava: 'Se não esperas, não encontrarás o inesperado"'. Este não é um sonho idealista, mas uma boa e saudável utopia, que se pode desejar e começar a fazer, fazendo-a práxis do cotidiano. Se utopia é o que não tem lugar no presente, entendemos que seja possível ao seu tempo. 


\section{REFERÊNCIAS}

BAUMAN, Z. O mal-estar da pós-modernidade. Rio de Janeiro: Zahar, 1998.

CAMARGO, D. Jung e Morin: crítica do sujeito moderno e suas implicações na educação. São Paulo: Xamã, 2007.

CIAMPA, A. da C. A estória do Severino e a história da Severina. 3. ed. São Paulo: Brasiliense, 1993.

FOUCAULT, M. Microfisica do poder. 21. ed. Rio de Janeiro: Graal, 2005.

FREIRE, P. A educação na cidade. São Paulo: Cortez, 1991.

GUATTARI, F. As três ecologias. Campinas: Papirus, 1990.

LISPECTOR, Clarice. Um sopro de vida - pulsações. São Paulo: Rocco, 1999.

MORIN, E. O Método 6: Ética. Porto Alegre: Sulina, 2005.

MORIN, E.; NAIR, S. Uma política de civilização. Lisboa: Instituto Piaget, 1997.

PESSOA, F. O Eu profundo e os outros Eus. 10. ed. Rio de Janeiro: Nova Fronteira, 1980.

PETRAGLIA, I. Sete idéias norteadoras da relação educação/complexidade. In: ALMEIDA, C.; PETRAGLIA, I. (Org.). Estudos de complexidade. São Paulo: Xamã, 2006, p. 23-36.

Texto recebido em 16 de abril de 2008 . Texto aprovado em 30 de junho de 2008. 